Assessment of Left Ventricular Diastolic Function in Children Undegoing Hemodialysis Using Various Doppler Techniques

Ljiljana S. Sulovic ${ }^{1}$,Vladimir Sulovic ${ }^{2}$, Zorica Zivkovic ${ }^{3}$, Jovan Zivkovic $^{3}$, Maja Vasic ${ }^{1}$, Nenad Sulovic ${ }^{4}$,

${ }^{1}$ Children's Hospital, Department of Pediatric Cardiology, Medical Faculty University of Pristina in Kosovska Mitrovica, Serbia

${ }^{2}$ Medical Faculty University in Belgrade, Serbia

${ }^{3}$ Children's Hospital, Department of Pediatric Nefrology, Medical Faculty University of Pristina in Kosovska Mitrovica, Serbia

4Medical Faculty, Clinic of Gynecology and Obstetrics, University of Pristina in Kosovska Mitrovica, Serbia

Corresponding Author:

Ljiljana Sulovic

Department of Cardiology, Children's Hospital

Medical Faculty

University of Pristina,in Kosovska Mitrovica

Anri Didan bb. Kosovska Mitrovica, Serbia

Home address: Tose Jovanovica 16, Belgrade Serbia

Tel: +381666060604; +38128498298

E-mail: 1jiljanasulovic64@gmail.com 


\begin{abstract}
:
Assessment of cardiac function is the leading parameter when evaluating the state of the cardiovascular system of patients undergoing chronic hemodialysis. The aim of the paper: to assess the state of the cardiovascular system of these patients using new sensitive echocardiography and Doppler techniques and thus advance the prevention of cardiovascular disease. Method: Twenty children with end-stage renal insufficiency on chronic hemodialysis and twenty healthy controls underwent echocardiographic monitoring using standard Doppler and tissue Doppler imaging. Structural and functional changes in the left ventricle were evaluated. Results: Patients on hemodialysis had significantly greater left ventricular mass indices compared to the controls $(p<0.001)$. The patients on hemodialysis had preserved systolic function-their fractional shortening, ejection fraction and Sm (systolic myocardial velocity) did not differ significantly compared to the controls $(\mathrm{p}>0.05)$. Early diastolic function in children on hemodialysis was also preserved: the E/A and Em/Am ratio did not differ significantly from the control group $(p>0.05)$. Children on hemodialysis exhibited impaired late diastolic function (compliance index), that is, considerably higher E/Em compared to controls $(\mathrm{p}<0.00)$. Myocardial Performance Index values showed statistically significant elevation in children on hemodialysis compared to the control group $(\mathrm{p}<0.001)$. Conclusion: Tissue Doppler in tandem with conventional Pulsed Doppler can provide additional information on left ventricular filling pressures $(\mathrm{E} / \mathrm{Em})$ in children on hemodialysis. It is therefore recommended to perform routine measuring of Em waves and the E/Em ratio, not only in order to evaluate myocardial relaxation and ventricular filling pressures, but primarily to stratify risk and provide a prognosis.
\end{abstract}


Keywords: chronic kidney disease; hemodialysis; cardiovascular disease; echocardiography; child 
INTRODUCTION: Advances in the technological and therapeutic methods of renal replacement therapy in children with chronic kidney disease have extended the lives of the patients, while at the same time drawing greater attention to the presence of secondary complications. Cardiovascular complications are the leading cause of mortality and morbidity in children with end-stage renal disease treated with hemodialysis [1]. Though treatment with dialysis is usually a temporary measure prior to transplantation, the consequences of even relatively short-term dialysis still remain after successful childhood kidney transplantation[2]. Compared to the general population, the long-term survival rates of children with chronic kidney disease remain reduced [3].

Recent research has revealed the presence of early structural changes to the heart muscle in children with chronic kidney disease, especially those who have been undergoing hemodialysis for extended periods. The hypothesis of parallel vascular and cardiac adaptation is gaining currency and it has been suggested that the strain of pressure and volume could be the cause of parallel development of vascular and heart damage in children with chronic kidney disease [4,5].

Numerous recently concluded studies reveal that diastolic dysfunction is present in children with end-stage renal disease who are treated with hemodialysis, while systolic function long remains preserved [6,7]. The prevalence of diastolic dysfunction is greater in patients on chronic hemodialysis, the likely reason being the emergence of new Doppler techniques enabling the detection of diastolic cardiac dysfunction in its early stages [8].

Material and methods :

Study population

The study involved 20 children with end-stage renal insufficiency, who had been in a program of chronic hemodialysis - three times a week, for at least two years. The control group $(\mathrm{N}=20)$ consisted of healthy children who had been examined in a cardiologist's office and diagnosed with physiologic heart murmurs. Children similar in sex and age to the children on hemodialysis were selected. Ethical clearance was obtained from the Ethical Committee, while written informed consent and assent were obtained from 
parents - and patients, where applicable - conforming to the policy statement with respect to the Declaration of Helsinki.

Basic anthropometric measurements were taken of all subjects: height, body weight and body surface. They were used to define the body mass index according to the following formula: Body mass index $=$ Weight $(\mathrm{kg}) / \operatorname{Height}\left(\mathrm{m}^{2}\right) \times$ Height $\left(\mathrm{m}^{2}\right)$

Blood pressure was measured using a mercury sphygmomanometer immediately before the echocardiographic examinations. The mean value of three measurements of blood pressure, taken successively with ten-minute breaks, was taken as the final value.

Hypertension was defined as arterial blood pressure exceeding the 95th percentile for the patient's age, sex and height [9].

Echocardiography

All children were examined with standard echocardiographic techniques and tissue Doppler imaging using an Aspen (Acuson) device with multi-frequency probes, from 2.5 to 4 and from 5 to $7 \mathrm{MHz}$. All measurements were performed following the recommendations of the American Society of Echocardiography [10] using the mean value of three to five consecutive cardiac cycles.

M-mod, 2-D and Doppler echocardiography were performed initially, followed by Doppler tissue imaging techniques.

Left ventricular mass was calculated using the Devereux formula [11].

$$
\mathrm{LVM}=0 \text { 8(1 04((LVDD + PWT + IVS })-(\text { LVDD })))+06 \mathrm{~g}
$$

LVDD - ventricular diameter in diastole

PWT - posterior wall thickness

IVS - interventricular septum diameter

The left ventricular mass index was calculated by dividing left ventricular mass by height $\left(\mathrm{m}^{2,7)}\right.$ to minimize effects of age, gender, and overweight status.

Left ventricular hypertrophy was defined as left ventricular mass Index $>38 \mathrm{~g} / \mathrm{m}^{2,7}$, a value greater than the 95 th percentile of the pediatric population[12,13].

The relative thickness of the posterior wall was used to assess left ventricular geometry.

Relative wall thickness $<0,41$ - normal values in children [14]. 
The relative wall thickness was calculated as an index of the left ventricular geometric pattern: Relative wall thickness $=($ interventricular septum diameter + posterior wall thickness)/ ventricular diameter in diastole. Concentric left ventricular hypertrophy was defined as increased left ventricular mass Index and Relative wall thickness greater than the 95th percentile of pediatric patients $(\geq 0.41)$, eccentric left ventricular hypertrophy was defined as elevated left ventricular mass Index with normal Relative wall thickness, and concentric remodeling was defined as normal left ventricular mass Index but elevated Relative wall thickness.

The diameter of the inferior vena cava was measured in M-Mode and 2-D echocardopgraphy, 1.5 centimeters below the diaphragm in the hepatic segment, in a supine position during normal inhalation and exhalation [15]. In order to eliminate the broad individual variation of inferior vena cava diameter, the inferior vena cava index was determined from the ratio of inferior vena cava diameter and body surface area (VCI/BSA).

The index of inferior vena cava collapse was calculated using the following formula:

VCI inex $=$ VCI exp.-VCI insp. /VCI exp. X 100

In assessing systolic function, fractional shortening and ejection fraction values were used.

Fractional shortening $=$ enddiastolic volume - endsystolic volume /end-diastolic volume X 100

Ejection fraction $=($ enddiastolic diameter- endsystolic diameter $) /$ enddiastolic diameter X 100

Two Doppler techniques were used - conventional pulsed wave Doppler (PWD) and Doppler tissue imaging (DTI). Diastolic flow at the mitral valve was registered using the pulsed wave Doppler technique from a four-chamber view, measuring maximum velocities during the stage of fast diastolic filling - E wave (peak of early diastolic flow velocities) and during atrial contraction - A wave (peak of atrial flow velocities); deceleration time (DT) was measured too. In addition, the E/A ratio was calculated for every subject as one of the key parameters in assessing early diastolic ventricular function. Pulsed wave Doppler was also used to measure and estimate pulmonary vein 
flow profiles in S (systolic) wave, D (early diastolic) wave and AR (pulmonary venous atrial reversal) wave.

In imaging using the tissue Doppler technique, filters were set to exclude highfrequency signals. Tissue Doppler technique measurements were done on apical fourchamber views, with the sample volume of three or five milimeters being placed over the base of the lateral wall of the left ventricle (LV-DTI). This method permitted registering myocardial motion along the longitudinal axis in systole $(\mathrm{Sm}$ - systolic myocardial velocity), in the early diastolic phase (Em - early diastolic myocardial velocity) and in the atrial contraction phase (Am - late diastolic myocardial velocity). The values obtained were used to calculate the ratio of maximum myocardial movement velocity in diastole $(\mathrm{Em} / \mathrm{Am})$. Also, the tissue Doppler technique was used to measure isovolumic contraction time (IVCT), isovolumic relaxation time (IVRT) and ejection time (ET) $[16,17]$.

Late diastole was monitored using the left ventricular compliance index, i.e. the $\mathrm{E} /$ Em ratio (the ratio of maximum blood flow velocity and maximum myocardial motion velocity in the left ventricular rapid filling phase) [18].

In the end, as a special parameter, reliable in assessing global function (systolic and diastolic), the Tissue Doppler method was used to calculate the Myocardial Performance Index (Tei Index) according to the formula: Myocardial Performance Index index = (isovolumic contraction time+ isovolumic relaxation time/ ejection time. [19].

\section{Statistical methods:}

In analyzing primary data, descriptive statistical methodss and statistical hypothesis testing methods were used. Among descriptive statistical methods, we used the measure of central tendency (arithmejection timeic mean, median), the measure of variability (standard deviation and range) and relative numbers (indicators of structure). Among methods for testing statistical hypotheses, we used the independent samples t-test, the dependent samples t-test, the Mann-Whitney test and the Wilcoxon test. Statistical data was processed by the SPSS 21 software package. Statistical hypotheses were tested at a statistical significance level of 0.05. The Spearman and the Pearson rank correlation methods, which establish the relationship among observed group traits and their 
interconnectedness, as well as the linear trend, were applied in analyzing the connection among paramejection timeers obtained using the different Doppler techniques.

\section{RESULTS:}

The clinical characteristics of the subjects on hemodialysis and the control group are shown in Table 1. There were ten boys and ten girls in the hemodialysis group, while the control group consisted of 13 boys and seven girls $(p>0.05)$. The mean value of the age of the subjects undergoing hemodialysis did not differ with statistical significance from the mean value of the ages of the control group (12.8 \pm 4.19 vs.10.62 $\pm 3.56 ; p>0.05)$. There was no statistically significant difference among the Body mass index values in the groups $(\mathrm{p}>0.05)$.

The subjects on hemodialysis had higher values of cardiac frequency compared to the control group $(\mathrm{p}<0.000)$. The systolic and diastolic blood pressure elevation of the subjects on hemodialysis against the controls was statistically significant $(p<0.000)$. Table 2. shows the echocardiographic characteristics of the examined groups. The mean values of the diameter of the inferior vena cava $\left(\mathrm{mm} / \mathrm{m}^{2}\right)$ during exhalation and inhalation were statistically significantly higher in subjects on hemodialysis compared to the control group $(\mathrm{p}<0.05)$. The index of inferior vena cava collapse during inhalation was statistically significantly lower in subjects on hemodialysis compared to the controls $(p<0.05)$. The mean values of left ventricular dimension in systole, interventricular septal thickness, posterior wall thickness, and left atrium were statistically significantly higher in subjects on hemodialysis against the control group $(\mathrm{p}<0.001)$.

Left ventricular mass was greater in a statistically significant degree in subjects on hemodialysis than in the control group $(\mathrm{p}<0.000)$. The left ventricular mass Index $/ \mathrm{m}^{2,7}$ also exhibited statistically significant elevation in subjects on hemodialysis compared to the controls $(\mathrm{p}<0.005)$.

The correlation coefficient between the left ventricular mass Index and systolic and diastolic blood pressure showed a positive linear trend of correlation, but did not rise to levels of statistical significance $(r=0.413, p>0.05$ for systolic blood pressure and $\mathrm{r}=0,378, \mathrm{p}>0.05$ for diastolic blood pressure). 
Fractional shortening and ejection fraction values in the children on hemodialysis and in the control group did not different $(p>0.05)$. Left ventricular hypertrophy was found in $60 \%$ or 12 subjects on hemodialysis (normal values: left ventricular mass index $>38 / \mathrm{m}^{2,7}$ ).

Relative wall thickness values in patients with left ventricular hypertrophy formed the basis for estimates of cardiac remodeling. Eccentric left ventricular hypertrophy was found in 7 of 12 subjects (58\%), 3 of 12 subjects (25\%) had concentric left ventricular hypertrophy, while 2 of 12 (17\%) had concentric remodeling left ventricles .

Table 3. shows the values obtained using pulsed wave Doppler and Tissue Doppler imaging in patients on hemodialysis and in the control group.

Using pulsed wave Doppler, we monitored pulmonary venous flow; S, D and AR waves differed significantly between children on hemodialysis and the controls. Also, the $\mathrm{S} / \mathrm{D}$ ratio in children on hemodialysis was $<1$, a statistically significant difference compared to the control group $(\mathrm{p}<0.05)$. The $\mathrm{E}$ wave was significantly higher in subjects on hemodialysis, while the A wave did not differ statistically when compared to the control group. In patients on hemodialysis, the E/A ratio was not significantly lower than in the control group $(\mathrm{p}>0.005)$. $\mathrm{E} / \mathrm{A}<1$ was found in ten percent of hemodialysis patients. Subjects on hemodialysis had statistically significantly shorter deceleration time than the deceleration time of controls $(\mathrm{p}<0.05)$.

Sm wave mean values in hemodialysis patients exhibited no statistically significant difference compared to the control group ( $p>0.05)$. All children had Sm wave velocities above eight centimejection timeers, values that confirm that systolic function is preserved.

Em waves, Am waves and the Em/Am ratio did not differ significantly between the hemodialysis patients and controls ( $\mathrm{p}>0.05$ ). Individually, $\mathrm{Em} / \mathrm{Am}<1$ was found in 7 of 20 or $35 \%$ of the hemodialysis patients. E/Em ratio analysis gave a mean value of $8.58 \pm 1.47$. The mean value of the E/Em ratio in the control group was $7.11 \pm 0.97$. The E/Em ratio exhibited statistically significant difference in hemodialysis patients compared to the healthy children $(\mathrm{p}<0.001)$.

The children on hemodialysis had considerably extended isovolumic relaxation time compared to controls $(\mathrm{p}<0.001)$. 
The mean value of the Myocardial Performance Index in children on hemodialysis was significantly higher than in the control group $(p<0.000)$. The Myocardial Performance Index was in significant linear correlation with the E/A ratio $(\mathrm{r}=-0.4 ; \mathrm{p}<0.05)$ and the $\mathrm{Em} / \mathrm{Am}$ ratio $(\mathrm{r}=-0.5 ; \mathrm{p}<0.01)$ in children on hemodialysis, while the Myocardial Performance Index of children in the control group showed a significantly positive linear trend in relation to the $\mathrm{E} / \mathrm{Em}$ ratio $(\mathrm{r}=-0.45 ; \mathrm{p}<0.05)$.

\section{DISCUSSION:}

The results of our study confirm the high prevalence of left ventricular hypertrophy in patients on hemodialysis, most frequently with eccentric left ventricular remodeling. Also, a large number of authors believe that left ventricular hypertrophy develops early on in chronic kidney disease as a consequence of cardiac remodeling and the compensatory mechanisms that activate to preserve cardiac function. Many authors have shown left ventricular hypertrophy frequency in children in chronic kidney disease stages $2-4$ to be $20 \%$ to $30 \%$, while among patients on hemodialysis this frequency is $60 \%$ to $85 \%[1-4]$.

Reports published in 2010 confirmed that hypertension (masked or confirmed) was the strongest independent cause of left ventricular hypertrophy development in children in chronic kidney disease stages 2-4 [20]. According to various sources, the frequency of hypertension in children undergoing dialysis varies from $40 \%$ to $90 \%$ $[21,1,6]$. The NAPRTCS reports that hypertension develops very early in chronic kidney disease [22]. According to the data of the European Dialysis and Transplant Association, $55 \%$ of children on chronic hemodialysis receive hypertension treatment. Despite being treated, one third of all patients' blood pressure levels remain $10 \mathrm{mmHg}$ or more above the 95th percentile for the appropriate age, sex and height [23].

The frequency of hypertension in children on hemodialysis in our study was $63 \%$, even though around 45\% were receiving hypertension treatment - ACE inhibitors and/or $\mathrm{Ca}$ jon antagonists[24]. Lately, most pediatric nephrologists tend to be aggressive in treating hypertension in their hemodialysis patients, thus achieving bejection timeter control over the hypertension. Calcium channel blockers and ACE inhibitors have been selected as the first-line drugs in the treatment of the majority of children on 
hemodialysis [25]. Most authors suggest that not only choice of medication, but also other, non-pharmacological therapy, is important in this population, like limiting the intake of salt, maintaining volume status and adequate dry weight.

However, the connection between blood pressure and left ventricular hypertrophy is not always present or simple. The fact that left ventricular hypertrophy is not always highly correlated with arterial blood pressure suggests that increased left ventricular mass Index is reversible, especially in young patients with end-stage renal insufficiency since childhood [20,21]. Controlling the hypertension, hypervolemia and anemia permits the process of left ventricular hypertrophy regression in children. We also examined the link between left ventricular mass Index and blood pesure, but found no statistically significant correlation between these two parameters [26,27].

The quality of dialysis greatly affects patients' morbidity and mortality rates. Therefore we strove that dialysis be as efficient as possible, while determining dialysis adequacy became a necessity in our daily work. Optimizing dialysis treatment demands great attention. On-line clearance monitoring (OCM) modules permit precise and continued measurement of the dialysis dose achieved. The unit used for dialysis dose is the $\mathrm{Kt} / \mathrm{V}$ index ( $\mathrm{K}$ - dialyzer urea clearance; $\mathrm{t}$ - dialysis time and $\mathrm{V}$ - total body water) measured in real time.

Echocardiographic measurement of the inferior vena cava collapse index cannot be used as a separate parameter, but in combination with other parameters may improve the monitoring of hydration and the quality of life of the hemodialysis patient.

Based on our results, we may conclude that all the children on hemodialysis and the children in the control group had preserved systolic function.

However, several recent reports have found subtle changes in the mechanics of the left ventricular wall by monitoring midwall shortening (mSF), which is considered more precise in assessing left ventricular function than fractional shortening. Abnormal $\mathrm{mSF}(<14 \%)$ was found in $25 \%$ of patients in chronic kidney disease stages $2-4$ in spite of normal shortening fractions. The prevalence of subclinical systolic dysfunction was greater in patients on hemodialysis $(40 \%)$ than in patients with chronic kidney disease stage 2-4 (9\%), but improved after kidney transplants (12\%). Therefore, abnormalities in left ventricular wall mechanics appear in pediatric patients with progressive renal 
dysfunction, while the presence of abnormal mSF could mark the beginning of maladaptive changes in the left ventricle in response to existing stimuli. Some new reports on investigation of left ventricular systole showing that chronic kidney disease patients have elevated left ventricular performance at rest support this. However, children on hemodialysis have chronically reduced contractile reserves under load due to lower perfusion and increased myocardial stunning, similarly to adults on hemodialysis[27].

Investigation of mitral flow velocity is the most broadly used method to assess diastolic left ventricular function. Though the mean values (E wave) in the children on hemodialysis were significantly higher than in the controls, there was no statistically significant difference between the hemodialysis patients and the control group in their E/A ratio values. In all likelihood, pre-dialysis hypervolemia masks early reduction of diastolic filling producing false normal values (pseudonormalization) for transmitral flow. In our results, we noticed statistically significant shortness of deceleration time in hemodialysis subjects compared to controls, which may indicate the existence of pseudonormalization as a second stage of diastolic dysfunction. Also, using pulsed wave Doppler, we found modified flow profiles in pulmonary veins, in line with the pseudonormalization type (second stage diastolic dysfunction). $\mathrm{S} / \mathrm{D}$ ratio $<1 ; \mathrm{p}<0.01$ compared to controls. AR wave velocity differed significantly compared to the control group $(\mathrm{p}<0.001)$.

Though we were unable to detect clearly the existence of early diastolic dysfunction of the myocardium using Tissue Doppler imaging in hemodialysis subjects, it is an important observation of our study that children on chronic dialysis have impaired left ventricular compliance, which manifests as increased left ventricular filling pressure, i.e. a higher E/Em ratio, obtained through a combination of pulsed wave Doppler and Tissue Doppler paramejection timeers.

Nagueh ejection time al.and other authors suggest that the E/Em ratio may be used, like left ventricular filling pressure, for assessing end-diastole left ventricular compliance, especially in patient with preserved systolic function. On a sample of 125 adults with normal and impaired diastolic function, Nagueh ejection time al. showed that the E/Em ratio is very reliable when estimating filling pressure, that is, capillary wedge pressure (obtained through cardiac cathejection timeerization). In healthy persons 
and asymptomatic patients (impaired relaxation), the ratio was under 8 , while in patients exhibiting symptoms of cardiac insufficiency (pseudonormal form) it was $18 \pm 4$. This study showed that E/Em $>10$ indicates mean capillary wedge pressure in excess of 15 $\mathrm{mmHg}$ with a sensitivity rate of $97 \%$ and a specificity rate of $78 \% .{ }^{16}$ Wang et al. found that Em and E/Em were excellent predictive indices of mortality in adult patients with weakened left ventricular systolic function. Hence routine measuring of Em waves and the E/Em ratio are recommended not only to assess myocardial relaxation and ventricular filling pressure, but first of all to stratify risk and give a prognosis [17].

Many recent studies [18,19,28] follow Myocardial Performance Index index values in patients with end-stage renal insufficiency. In most of these patients, Myocardial Performance Index index values were high, statistically clearly different from the healthy population and indicative of impaired global cardiac function.

A study by Koga [29] ejection time al following 35 children on dialysis found significantly increased Myocardial Performance Index index values (0.42-0.51) as a consequence of extended times of isovolumic relaxation and shortened ejection time, without changes to deceleration time or isovolumic contraction time.

In our study, the Myocardial Performance Index (Tei index) was measured using the TDI methods. Myocardial Performance Index values were significantly higher in subjects on hemodialysis compared to the control group. In this patient group, we noted significantly extended mean isovolumic relaxation time values, shortened deceleration time in subjects on hemodialysis, while isovolumic contraction time and ejection time did not change notably.

Further, one important observation of our study is that children on chronic hemodialysis also have larger left ventricular sizes than the control group. In diastole, the left atrium chamber is directly exposed to left ventricular filling pressure through the open mitral valve. Hence the increased left atrium dimensions are probably a consequence of left venticular diastolic dysfunction. Diastolic dysfunction and left atrium enlargement in these patients can partly be ascribed to an elevated left ventricular mass index. In our study, we found positive linear correlation between left atrium dimensions and left ventricular mass Inex, but it did not rise to the level of statistical significance, which is in accordance with other studies $[30,18]$. 
In many studies, left atrium dimensions are very important to monitoring diastolic function. The size of the left atrium is weakly preload-dependent, so following left atrium dimensions is considered to be more reliable than transmitral flow when assessing diastolic dysfunction. Also, increased left atrium dimensions and volume are considered a poor prognostic indicator[2,30].

Conclusion: The close connection bejection timeween chronic kidney disease and cardiovascular changes points to the necessity of a multidisciplinary approach (by a pediatric nephrologist and cardiologist) in arriving at the optimal treatment of chronic kidney disease patients undergoing chronic hemodialysis therapy. An important finding of our study was that an individual evaluation of the cardiovascular system of patients on hemodialysis can considerably delay and improve the cardiovascular outcome and lead to improved quality of life for each patient individually. Monitoring the condition of the cardiovascular system of these patients necessitates evaluating the structure and function of the heart, which should be done using conventional echocardiographic methods and tissue Doppler, while combining the pulsed wave Doppler and Tissue Doppler imaging paramejection timeers is also necessary. Routine measuring of Em waves and the E/Em ratio is recommended, not only in order to assess myocardial relaxation and ventricular filling pressure, but first of all in order to stratify risk and provide a prognosis.

Financial support

"This research has not received a concrejection timee donation from any agency for financing, commercial or non-profit sectors".

Conflict of Interest.

" Nothing. " 
References:

1. Shroff R, Weaver DJ and Mitsnefes M. Cardiovascular complications in children with chronic kidney disease Nat. Rev. Nephrol.2011;(7):642-649.

2. Foster BJ, Dahhou M, Zhang X, Platt RW, Hanley JA. Change in mortality risk over tim in young kidney transplant recipients. Am J Transplant 2011;(11):2432-2442.

3. Mitsnefes M, Benjamin L, Dahhou, Zhang X, Foster BJ. Mortality risk among children initially treated with dialysis for end stagekidney disease, 1990-2010. Jama 2013;(309-18):1921-1929.

4. Mitsnefes M. Cardiovascular Disease in Children with Chronic Kidney Disease J Am Soc Nephrol. 2012;23:578-585.

5. Nickovic Vanja P Miric Dijana J Kisic Bojana M Kocic Hristina Stojanovic Marko Buttice Salvatore Kocic Gordana M Oxidative stress, NOx/L-arginine ratio and glutathione/glutathione S-transferase ratio as predictors of "sterile inflammation' in patients with alcoholic cirrhosis and hepatorenal syndrome type II RENAL FAILURE. 2018;40(1):340-349

6. Adiele DK, Okafor HU, Ojinnaka NC, Onwubere BJ, Odejection timeunde OI, ejection time al. Echocardiographic Findings in Children with Chronic Kidney Disease as Seen in the Resource-Limited Sejection timeting. J Nephrol Ther 2014;(4)3:1 58 doi:10.4172/2161-0959.1000158.

7. Lindblad YT, Axelsson J, Balzano R, Vavilis G, Chromek M, Celsi G. ejection time al. Left ventricular diastolic dysfunction by tissue Doppler echocardiography in pediatric chronic kidney disease. Pediatr Nephrol. 2013; 28(10):2003-2013.

8. Civilibal M, Caliskan SOfla H, ejection time al. Left ventricular function by conventional and tissue Doppler' echocardiography in paediatric dialysis patients. Nephrology 2009; 14:636-642

9. Blood Pressure Measurement in Children From the National High Blood Pressure Education Program Working Group on High Blood Pressure in Children and Adolescents. NIH Publication 07-5268 May 2007

10. Sahn DJ, DeMaria A, Kisslo J, ejection time al. Committee on M-Mode Standardizations of the American Sociejection timey of Echocardiography. 
$\underline{\text { Recommendations regarding quantitation in M-mode echocardiography:results of a }}$ survey of echocardiographic measurements. Circulation 1978;58:107.

11. Devereux RB, Alonso DR, Lutas EM, Gottlieb GJ, Campo E, Sachs I, Reichek N Echocardiographic assessment of left ventricular hypertrophy: comparison to necropsy findings. Am J Cardiol. 1986;57:450-458.

12. Khoury PR, Mitsnefes M, Daniels SR and Kimball TR. Age-specific reference intervals for indexed left ventricular mass in children. J Am Soc Echocardiogr. 2009;22:709-14.

13. Matteucci MC, Wuhl E, Picca S, Mastrostefano A, Rinelli G, Romano C, ejection time al. Left ventricular geomejection timery in children with mild to moderate chronic renal insufficiency. J Am Soc Nephrol. 2006;17:218-226.

14. Murilo Foppa, Bruce BD, Luis EP, ejection time al.Echocardiography-based left ventricular mass estimation. How should we define hypertrophy? Cardiovascular ultrasound 2005; 3:17-19.

15. Sonmez F, Mir, Ozyurek AR. ejection time al.The adjustment of post dialysis dry weight based on non-invasive measurements in children. Nephrol Dial Transplant. 1996;11:1564-1657.

16. Nagueh SF, Middlejection timeon KJ, Kopelen HA, Zoghbi WA, Quinones MA. Doppler tissue imaging: a noninvasive technique for evaluation of left ventricular relaxation and estimation of filling pressures. J Am Coll Cardiol. 1997;30:15271533.

17. Wang M, Yip GW, Wang AY, Zhang Y, Ho PY, Tse MK, ejection time al. Peak early diastolic mitral annulus velocity by tissue Doppler imaging adds independent and incremental prognostic value. J Am Coll Cardiol 2003;41:820-6.

18. UçarT, Tutar E, and Yalçınkaya F. Global left-ventricular function by tissue Doppler imaging in pediatric dialysis patients Pediatr Nephrol. 2008: 23:779-785

19. Myocardial Performance Index C.:New non-invasive index for combined systolic and diastolic ventricular function. J Cardiol. 1995;26:135-6

20. Mitsnefes M, Flynn J, Cohn S, Samuels J, Blydt-Hansen T, Saland J, ejection time al. Masked hypertension associated with left ventricular hypertrophy in children with CHRONIC KIDNEY DISEASE . J Am Soc Nephrol. 2010;21:137-144 
21. Flynn J. Hypertension in the young: epidemiology, sequelae, therapy. Nephrol Dialysis Transplant. 2009; 24:370-375.

22. NAPRTCS: a report of the North American Pediatric Renal Transplant Cooperative Study (NAPRTCS). J Am Soc Nephrol. 2003;14:2618-2622.

23. ERA-EDTA Registry Annual Report 2008. Academic Medical Center, Department of Medical Informatics, Amsterdam, The Nejection timeherlands,2010

24. Sulovic Lj. Risk factors for cardiovascular disease in children on chronic hemodialysis - Traditional (general) risk factors, Part I Vojnosanit Pregl 2016; 73(12): 1149-1154.

25. Gupta D, Chaturvedi S. Chand S and Agarwal I .Role of 24-h ambulatory blood pressure monitoring in children with chronic kidney disease. Indian J Nephrol. 2015;25(6):355-361

26. Kupferman JC, Aronson-Friedman L, Cox C, Flynn J, Furth S, Warady B $\mid$ and Mitsnefes M, the CKiD Study Group. Left Ventricular Hypertrophy Regression in Children with CHRONIC KIDNEY DISEASE J Am Soc Nephrol. 2014;25:167174.

27. Weaver DJ. Kimball TR, Koury PR. and Mitsnefes M. Cardiac output and associated left ventricular hypertrophy in pediatric chronic kidney disease. Pediatr. Nephrol. 2009;24:565-570.

28. Tafreshi RI, Human N, Otukesh H. and Nikavar A. Evaluation of Combined Left Ventricular Function using the Myocardial Performance Index in Children with Chronic Kidney Disease. Echocardiography,2011;28: 97-103.

29. Koga S, Ikeda T, Influence of hemodialysis on echocardiographic Doppler indices of the left ventricle:Changes in paramejection timeers of sistolic and diastolic function and Myocardial Performance Index index(abstrakt)Clinical nephrologu 2003;53:180185.

30. Demirpence A, Guven B, Mese T, Serdaroglu E, Yilmazer MM, Firuzan E, Tavli V. Evaluation of left atrial functions in children with chronic renal failure. Anadolu Kardiyol Derg.2014;May;14(3):280-5. 
Table 1. Clinical characteristics in patients on hemodialysis treatment and control group

\begin{tabular}{llll}
\hline & $\begin{array}{l}\text { HD }(\mathrm{n}=20) \\
\text { Mean } \pm \text { SD }\end{array}$ & $\begin{array}{l}\text { Control }(\mathrm{n}=20) \\
\text { Mean } \pm \text { SD }\end{array}$ & P \\
\hline Male/female & $10 / 10$ & $13 / 7$ & $\mathrm{~ns}$ \\
Age & $12.85 \pm 4.19$ & $10.62 \pm 3.58$ & $\mathrm{~ns}$ \\
BMI $\left(\mathrm{kg} / \mathrm{m}^{2}\right)$ & $1.17 \pm 0.32$ & $1.16 \pm 0.31$ & $\mathrm{~ns}$ \\
HR (beats/min) & $103.3 \pm 9.83$ & $77.4 \pm 12.12$ & $0.000^{*}$ \\
SBP $(\mathrm{mmHg})$ & $130.25 \pm 16.87$ & $103-95 \pm 15.24$ & $0.000^{*}$ \\
DBP $(\mathrm{mmHg})$ & $90.1 \pm 15.10$ & $67.60 \pm 10.51$ & $0.000^{*}$ \\
\hline
\end{tabular}

Data are presented as mean \pm standard deviation.

SD-standard deviation,

HD- hemodialysis,

BMI- body mass index,

HR- Heart rate,

SBP- Sistolic blood pressure,

DBP- Diastolic blood pressure,

NS- not significant. 
Tabela 2. Clinical characteristics and echocardiographic measurements in patients on hemodialysis treatment and control group

\begin{tabular}{llll}
\hline & \multicolumn{2}{c}{ HD } & \multicolumn{1}{c}{ Control } \\
& & \multicolumn{1}{c}{$\mathrm{P}$} \\
\hline VCI exp. $\left(\mathrm{mm} / \mathrm{m}^{2}\right)$ & $11.78 \pm 3.69$ & $9.59 \pm 2.79$ & $0.041^{*}$ \\
VCI insp. $\left(\mathrm{mm} / \mathrm{m}^{2}\right)$ & $5.81 \pm 3.23$ & $3.65 \pm 2.09$ & $0.017^{*}$ \\
VCI index \% & $51.20 \pm 19.82$ & $63.10 \pm 14.82$ & $0.038^{*}$ \\
LVMg & $96.16 \pm 33.68$ & $64.05 \pm 33.67$ & $0.000^{*}$ \\
LVMI $\left(\mathrm{g} / \mathrm{m}^{2} \cdot 7\right)$ & $41.1 \pm 13.2$ & $25.65 \pm 7.36$ & $0.005^{*}$ \\
LVDD $(\mathrm{mm})$ & $40.45 \pm 4.49$ & $36.95 \pm 6.64$ & $\mathrm{~ns}$ \\
LVSD $(\mathrm{mm})$ & $25.15 \pm 3.17$ & $21.90 \pm 4.22$ & $0.009^{*}$ \\
IVSD $(\mathrm{mm})$ & $8.04 \pm 1.68$ & $6.47 . \pm 1.06$ & $0.000^{*}$ \\
PWT $(\mathrm{mm})$ & $8.10 \pm 1.77$ & $6.34 \pm 1.01$ & $0.001^{*}$ \\
LA $(\mathrm{mm})$ & $25.95 \pm 4.48$ & $21.75 \pm 4.18$ & $0.004^{*}$ \\
EF $(\%)$ & $59.1 \pm 8.7$ & $63.3 \pm 5.06$ & $\mathrm{~ns}$ \\
FS $(\%)$ & $37 \pm 5$ & $40 \pm 6$ & $\mathrm{~ns}$ \\
& & & \\
\hline
\end{tabular}

Values are presented as mean values \pm SD.

SD-standard deviation,

EF-Ejection fraction,

FS-Fractional shortening,

LVDD-Left Ventricular Diameter in Diastole,

IVSD-Interventricular Septum in Diastole,

PWT-Posterior Wall Thickness .

LVMI-left ventricular mass index,

NS-not significant 
Tabela 3. Pulsed Doppler and tusse Doppler measurements in patients on hemodialysis treatment and control group

\begin{tabular}{|c|c|c|c|}
\hline & $\begin{array}{l}\text { HD } \\
(\mathrm{N}=20)\end{array}$ & $\begin{array}{l}\text { Control } \\
(\mathrm{N}=20)\end{array}$ & $\mathrm{p}$ \\
\hline $\mathrm{S}(\mathrm{cm} / \mathrm{s})$ & $80.70 \pm 10.58$ & $72.45 \pm 9.30$ & $0.013 *$ \\
\hline $\mathrm{D}(\mathrm{cm} / \mathrm{s})$ & $81.00 \pm 12.87$ & $68.50 \pm 13.19$ & $0.004 *$ \\
\hline S/D & $0.99 \pm 0.12$ & $1.05 \pm 0.18$ & $0.03 *$ \\
\hline $\mathrm{AR}(\mathrm{cm} / \mathrm{s})$ & $19.55 \pm 3.93$ & $16.10 \pm 4.81$ & $0.017 *$ \\
\hline Peak E $(\mathrm{cm} / \mathrm{s})$ & $139.9 \pm 17.18$ & $123.65 \pm 18.96$ & $0.008^{*}$ \\
\hline Peak A $(\mathrm{cm} / \mathrm{s})$ & $95.1 \pm 13.12$ & $80.35 \pm 11.65$ & ns \\
\hline $\mathrm{E} / \mathrm{A}$ ratio & $1.59 \pm 0.36$ & $1.43 \pm 0.16$ & $0.005^{*}$ \\
\hline DT & $100.65 \pm 21.2$ & $113.65 \pm 17.24$ & $0.03 *$ \\
\hline $\mathrm{Sm}(\mathrm{cm} / \mathrm{s})$ & $14.58 \pm 1.79$ & $13.96 \pm 17.6$ & ns \\
\hline $\operatorname{Em}(\mathrm{cm} / \mathrm{s})$ & $16.15 \pm 2.38$ & $16.91 \pm 3.14$ & ns \\
\hline $\operatorname{Am}(\mathrm{cm} / \mathrm{s})$ & $13.02 \pm 2.16$ & $13.47 \pm 2.85$ & ns \\
\hline Em/Am ratio & $1.21 \pm 0.29$ & $1.25 \pm 0.10$ & ns \\
\hline $\mathrm{E} /$ Em ratio & $8.58 \pm 1.47$ & $7.11 \pm 0.97$ & $0.001 *$ \\
\hline IVRT (ms) & $70.6 \pm 13.69$ & $63.12 \pm 10.48$ & $0.009^{*}$ \\
\hline IVCT (ms) & $59.55 \pm 14.93$ & $60.3 \pm 10.75$ & ns \\
\hline Tei Index (ms) & $0.47 \pm 0.07$ & $0.42 \pm 0.04$ & $0.000^{*}$ \\
\hline ET (ms) & $259.2 \pm 58.28$ & $272.15 \pm 41.0$ & ns \\
\hline
\end{tabular}

$\mathrm{S}(\mathrm{cm} / \mathrm{s})$ systolic velocity,

$\mathrm{D}(\mathrm{cm} / \mathrm{s})$ diastolic velocity,

$\operatorname{AR}(\mathrm{cm} / \mathrm{s})$ pulmonary venous atrial reversa,

$\mathrm{S} / \mathrm{D}$ ratio between the systolic and diastolic peak pulsed pulmonary venous Doppler velocities,

E-peak early-diastolic velocity,

A-peak late-diastolic velocity,

E/A ratio between the early and atrial peak pulsed mitral Doppler velocities,

Sm- Myocardial systolic wave,

Em- peak early-diastolic mitral annular velocity,

Am- peak late-diastolic mitral annular velocity,

Em/Am- ratio of early diastolic myocardial velocity and late myocardial velocity,

E/Em- ratio of maximum blood flow velocity and maximum myocardial motion velocity,

Tei Index-(MPI-Myocardial Performance Index), 
IVCT-isovolumic contraction time,

IVRT-isovolumic relaxation time,

ET- ejection time, 